\title{
Dietary evenness, prey choice, and human-environment interactions
}

\author{
Emily Lena Jones* \\ Department of Anthropology, Box 353100, University of Washington, Seattle, WA 98195, USA
}

Received 24 May 2002; received in revised form 21 August 2003; accepted 28 August 2003

\begin{abstract}
Although measures of evenness of archaeological faunas are increasingly used in zooarchaeological analyses, the widely accepted hypothesis that increasing evenness should indicate increasing dietary breadth has not been tested. In this paper, I examine three factors that can contribute to changing evenness values - changing encounter rates with high-ranked prey types, changing diet breadth, and similarity between the return rates of the highest-ranked resources - and discuss ways of controlling the latter two factors. I then test the "evenness hypothesis" using ethnographic data collected by Smith [E.A. Smith, Evolutionary Ecology and the Analysis of Human Foraging Behavior: An Inuit Example from the East Coast of Hudson Bay, Ph.D. thesis, Cornell University, 1980, E.A. Smith, Inujjamiut Foraging Strategies: Evolutionary Ecology of an Arctic Hunting Economy, Aldine de Gruyter, Hawthorne, NY, 1991] in Inukjuak, northern Canada. Although the results support the evenness hypothesis, they also show that the nature of archaeological data may make evenness measures difficult to use accurately. Evenness can be used to understand changing prehistoric encounter rates with prey, but many conditions must be met for it to do so.
\end{abstract}

(C) 2003 Elsevier Ltd. All rights reserved.

Keywords: Diversity; Evenness; Zooarchaeology; Optimal foraging theory; Prey choice; Arctic

Measures of evenness, which quantify the degree to which classes within an assemblage are equally represented by the individuals within that assemblage, have been used by zooarchaeologists for over three decades. These measures were first introduced to zooarchaeology by Wing [40,41]; later, Grayson [15,16] presented them to a wider archaeological audience. Despite this early exposure, until recently archaeologists have routinely preferred other measures of diversity in assessing zooarchaeological assemblages. In the past several years, evenness measures have been increasingly used by archaeologists working within an optimal foraging theory framework (i.e., [19,21,28,36]). Understanding of what evenness means within an archaeological context, however, has lagged far behind comparable work done in ecology.

In ecological studies, evenness is routinely included in studies of species diversity in different environments, usually in conjunction with other measures of diversity,

\footnotetext{
* Tel.: +1-206-543-5240; fax: +1-206-543-5285.

E-mail address: emljones@u.washington.edu (E.L. Jones).
}

such as richness or heterogeneity indices [22,23,27,43]. Evenness has also been used by some conservation biologists to consider the effect of human behavior on species diversity $[1,12,13,32,39]$. Interestingly enough, these studies have found that human impacts on overall species evenness vary dramatically from situation to situation, depending on the characteristics of the relevant environment, the particular species being considered, and the ways in which humans have impacted the environment.

Recent papers have also shown that evenness can be a useful measure within optimal foraging-based studies of human-environment interactions [19,21,28,36]. Although these papers apply evenness in different archaeological contexts, all of them see changing evenness through time as reflecting changing encounter rates with prey. Evenness is not the only line of evidence presented by these authors; relative abundance indices and/or species richness are also used to make an argument for changing encounter rates. The changes in encounter rates are in some cases attributed to human impact on the landscape, in others to the effects of climate change. All the authors see increasing evenness 
as reflecting increasing dietary breadth, or the decreasing availability of preferred prey types. Although evenness provides key evidence in the arguments that each of these authors make, little attention is given to describing why evenness is expected to change through time as it does. Despite the recent florescence of papers using evenness with optimal foraging theory, there is no in-depth analysis of how the prey choice model allows researchers to make the prediction that evenness will increase as encounter rates with higher-ranked prey decrease. Do encounter rates really drive evenness, or can other factors influence it as well? As yet, there is no answer to this question.

Given the increasing popularity of optimal foraging theory-based studies of archaeological subsistence [42], and the sometimes dramatic results achieved by authors already making use of evenness [19,21,36], an examination of what evenness actually measures is essential. The hypothesis that dietary evenness can, under certain conditions, record changes in prehistoric prey encounter rates has not been tested, in part because the use of evenness has so far been confined to archaeological studies, and the nature of archaeological data makes such an argument difficult to test. With ethnographic foraging data and information on actual encounter rates, however, the "evenness hypothesis" can be examined more directly. In this paper, I consider the meaning of evenness in both archaeological and ethnographic settings, and conduct a test of the evenness hypothesis with ethnographic data collected by Smith $[33,34]$ at Inukjuak, northern Canada. I then explore how evenness changes in an archaeological setting, reanalyzing Smith's data as if it were archaeological.

\section{Evenness and optimal foraging theory}

The optimal foraging theory-based work that uses evenness has all been based on predictions derived from the prey choice model. Therefore, in this paper I consider evenness within the context of the prey choice model, which predicts the resources a forager will pursue once a resource has been encountered, given certain assumptions and parameter values $[18,24,35,42]$.

The prey choice model assumes that resources are encountered sequentially, randomly, and as a function of (though not necessarily proportionally to) their abundance in a given area or "patch". Potential prey types are placed in a rank-ordered set, with the ranking based on their post-encounter energetic return ratesthat is, how much energy (or some other currency) is returned from prey of a given type given pursuit and handling costs incurred. In archaeological contexts, where post-encounter return rates cannot be measured, faunal resources are generally ranked according to size, with larger mammals (up to a certain size) assumed to have a higher post-encounter return rate than smaller ones. Although this body-size correlation does have some ethnographic support [3-6,35], counter examples do exist $[2,14]$. In particular, situations in which small prey are taken en masse upset the body-size correlation $[9,18,25]$.

One clear conclusion from the prey choice model is that resources will be added to, or dropped from, a forager's optimal set according to efficiency rank order. As encounter rates with higher-ranked resources decline sufficiently, a wider and wider array of increasingly lower-ranked prey types will be taken. A forager's environment, therefore, will consist of a suite of potential resources ranked along a continuum from high to low. We can roughly divide these resources into higherranked resources (those resources that are so highly ranked that they will always be taken upon encounter) and lower-ranked resources (those prey items that will only be taken if encounter rates with higher-ranked resources decline below a certain point). Because lowerranked resources will be added to the diet in rank order as encounter rates with higher-ranked prey types decrease, the total numbers of lower-ranked resources in a forager's diet will not reflect the landscape abundance or scarcity of those resources, since their dietary abundances depend on encounter rates with higher-ranked resources [7].

Using the logic of the prey choice model, it follows that dietary evenness can be driven by three main parameters. One of these is that predicted by the "evenness hypothesis": the evenness of the diet should correspond to the evenness of encounter rates with the highest-ranked prey. However, two other factors can also influence dietary evenness: changing diet breadth, or the total number of prey types in the diet (which may, of course, be related to changing encounter rates), and the degree to which high-ranked prey items are similar in return rate. The difficulty of using evenness as a measure to understand the changing structure of animal communities is in teasing out which of these parameters is responsible for changing evenness values during any given time period. To use evenness to identify changes in encounter rates, we must be sure those rates, rather than changing diet breadth or relative evenness of prey return rates, are driving changing evenness values.

Fluctuations in diet breadth over long periods of time, where time-averaging comes into play, can cause a problem for archaeologists using evenness. A variable number of resources in the diet may cause evenness to increase or decrease, depending on exactly how the numbers are changing. The difference in evenness in this case, however, will be driven by the time-averaged changes in diet breadth, rather than by changes in encounter rates with higher-ranked prey. In archaeological assemblages, this problem can be solved by considering only resources that are sufficiently high-ranked to always be included in the diet. 


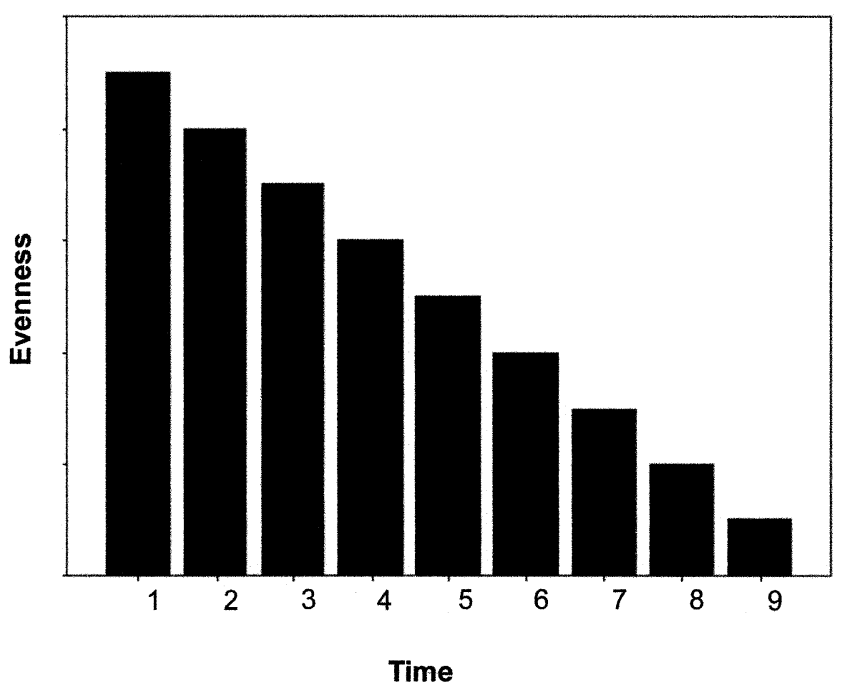

Fig. 1. Hypothetical evenness distribution given increasing abundance of one high-ranked prey type over nine time periods

Insofar as this is accomplished, one potential evenness response to increased landscape abundance of an "always-taken" high-ranked resource is a decline in evenness. As this prey type becomes increasingly abundant and forager encounter rates with this prey type increase, the less highly ranked prey items that were previously in the diet are dropped. The abundant higherranked resource increasingly dominates the assemblage and evenness declines. As encounter rates with this prey type decline, then evenness may increase as subsistence focuses on a wider variety of prey. Fig. 1 shows a hypothetical, expected distribution over nine time periods (1 through 9) in a situation where one or two very high-ranked species are increasing in abundance relative to less high-ranked prey.

However, if a number of high-ranked resources, all sufficiently high-ranked to be included in the diet, become increasingly equally abundant, then evenness may increase while total encounter rates with all highranked resources have increased as well. Fig. 2 shows a hypothetical expected distribution in this case; as time passes from 1 to 9 , evenness increases, because encounter rates with the highest ranked resources have increased. Even though the situation is similar to the one described earlier-high-ranked prey are increasing - the response of evenness measures is the opposite. How, then, can we understand what evenness values mean in varying situations?

A solution to this problem is provided by combining the evenness analysis with a series of other analyses. By combining an evenness analysis with an analysis of richness, or the number of taxa (NTAXA) incorporated in the diet, we can detect situations in which similar evenness values are associated with different diets. In addition, we must also consider the kinds of taxa that

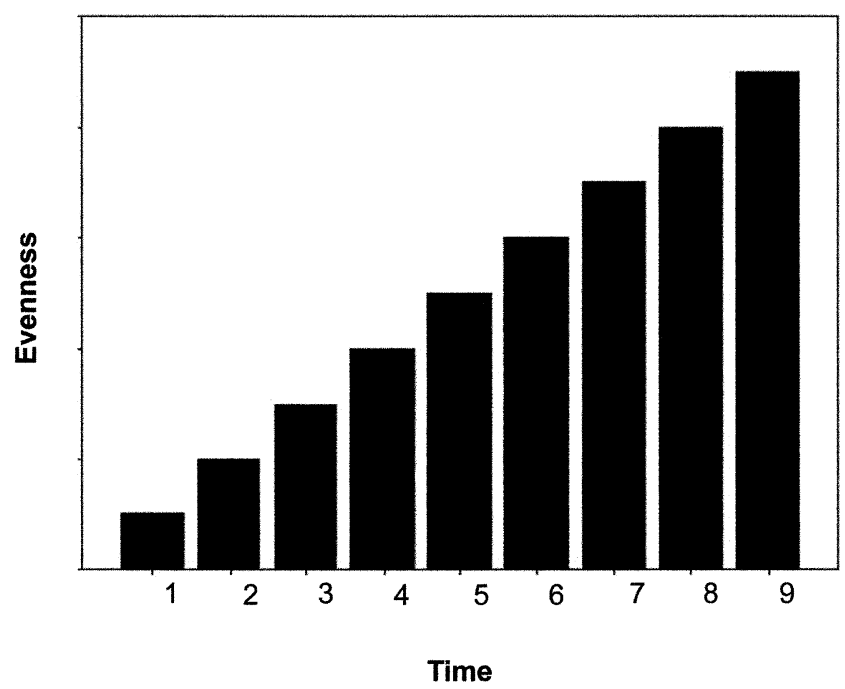

Fig. 2. Hypothetical evenness distribution given increasing abundance of several prey types with equal return rates over nine time periods.

are being included in the diet, and this can be done through an analysis of nestedness, the degree to which one species assemblage is a subset of a richer assemblage $[19,29]$. Increasing nestedness can indicate increasing encounter rates with a number of high-ranked species, so a combination of increasing richness and increasing nestedness may indicate a situation such as that depicted in Fig. 2. Thus, the combination of an evenness analysis, a richness analysis, and an analysis of nestedness will allow us to understand how the ranking of resources in a particular case will affect evenness values.

Using evenness as a measure of diversity in archaeological faunas, then, requires the analyst not only to examine changing numbers of high-ranked faunas through time, but also to consider what prey types are being added to and/or dropped from the diet through time. While these two potential confounding factors can be controlled fairly easily, however, there is a deeper problem behind them: understanding the ranked list upon which the whole analysis depends. Without a clear understanding of how resources are ranked, controlling for these confounding factors is impossible. As mentioned earlier, archaeologists cannot measure return rates directly, and so rely on proxies, most often using prey body size - but we know these proxies are imperfect [18,25,36-38].

\section{Does evenness work? A test with ethnographic data}

Many of the problems in using evenness measures that archaeologists must contend with will not apply in ethnographic situations. While we still must be sure that changing encounter rates, rather than changing diet breadth or relative evenness of prey return rates, are driving changing evenness values, the process of doing 
this is much simplified. Because ethnographers typically consider only a short period of time, the time averaging of changing diet breadths is not a problem-all resources collected during a year are "in the diet," and therefore there is no need to restrict analysis to the highest-ranked suite of resources. Similarly, in ethnographic contexts foraging return rates can be directly measured, and so the problem of evenness of return rates can be directly calculated, rather than inferred from analyses of richness and nestedness. The deeper problem-understanding the ranked list - is also not problematic, again because foraging return rates can be directly measured.

Here, I test Grayson et al.'s [21] evenness hypothesis using an ethnographic data set. In addition to allowing direct observation of critical variables, this approach also provides an opportunity to examine whether the body size proxy might be a sufficient measure for this level of analysis, despite the known problems with it $[2,14,18,25,36]$. Given the ethnographic context, I consider the entire diet; specifically, I examine the ratio of the high-ranked resources taken in a bimonthly period to all the resources taken during that period (HRR). HRR reflects the degree to which the diet is focused on the highest-ranked prey-types in the diet.

There are a number of different evenness measures, of which the most common are the evenness index derived from the Shannon diversity index (which I will refer to as Shannon's E) and the reciprocal of Simpson's index. Shannon's E is the ratio of observed evenness in a sample to the maximum possible evenness [26,30]. Shannon's E will always be a value between 0 and 1 , with 1 describing a sample where all taxa are equally abundant. This measure assumes that all the taxa in a community are accounted for in the sample.

Simpson's Dominance index (D), on the other hand, calculates the degree to which an assemblage is dominated by the most abundant taxon in the sample:

$D=\Sigma\left(\frac{n_{\mathrm{i}}\left(n_{\mathrm{i}}-1\right)}{N(N-1)}\right)$

where $n_{\mathrm{i}}$ is the number of individuals in a taxon and $N$ is the total number of individuals in the sample. As D increases, evenness decreases, and thus Simpson's index is usually expressed as 1/D. Like Shannon's E, Simpson's index (when expressed as 1/D) will increase as evenness increases, and decrease as evenness decreases. Unlike Shannon's E, however, Simpson's index is heavily weighted toward the most dominant taxa in the sample, and less sensitive to species richness as a whole [26]. Archaeological data may underestimate total species richness, which may make the reciprocal of Simpson's index a more appropriate measure for archaeological studies. This analysis is meant to repli-
Table 1

Common and scientific names of some species commonly taken by Inujjuamiut

\begin{tabular}{ll}
\hline Common name & Scientific name \\
\hline Bearded seal & Erignathus barbatus \\
Ringed seal & Phoca hispida \\
Beluga whale & Delphinapterus leucas \\
Caribou & Rangifer tarandus \\
Ptarmigan & Lagopus lagopus, L. mutus \\
Common eider & Somateria mollissima \\
Canada goose & Branta canadensis \\
Guillemot & Cepphus grylle \\
Arctic char & Salvelinus alpinus \\
Lake trout & S. namaycush \\
Brook trout & S. fontinalus \\
Lake whitefish & Coreogonus clupeaformis \\
Sculpin & Myoxocephalus spp. \\
\hline
\end{tabular}

cate an archaeological situation, and I thus chose to evaluate evenness using the reciprocal of Simpson's Dominance index, 1/D.

Since we know, based on inspection of the data and analysis of the resource return rates, that evenness of return rates and increasingly equal encounter rates are not driving evenness values for this data set, we would expect evenness to decrease as HRR increases if the "evenness hypothesis" is correct.

After the relationship between evenness and HRR is examined, I compare patterns of evenness to known seasonal availability of resources. If the "evenness hypothesis" is correct, we would expect HRR to be low and evenness to be high in seasons when the highestranked resources are not widely available, and HRR to be high and evenness to be low in seasons when the highest-ranked prey types are abundant.

Although there are some significant differences between the application of evenness in archaeological and ethnographic contexts, I have attempted to address these below.

\subsection{The Inujjuamiut case}

To test the "evenness hypothesis," I use subsistence data collected by Smith $[33,34]$ in and around Inukjuak, an Inuit village on the eastern shore of Hudson Bay, between July 1977 and August 1978. During the study period, there were about 600 Inujjuamiut in the village, participating in three major economic activities: foraging, handicrafts, and wage labor. Foraging included take of non-subsistence items (i.e., fox trapping for fur) as well as hunting for subsistence purposes. Table 1 provides a list of some of the prey items commonly taken by Inujjuamiut. The intense seasonality of the Arctic environment produces a specific annual cycle of foraging; thus, prey resources are discussed by season. Roughly, in the summer and fall most foraging effort is 
Table 2

Prey ranking based on energetic return and on kcal/individual ([34], pp. 181, 234)

\begin{tabular}{|c|c|c|c|c|}
\hline Common name & Post-encounter return rate $(\mathrm{kcal} / \mathrm{h})$ & Rank & Kcal/individual (edible portion) & Rank \\
\hline \multicolumn{5}{|l|}{ Summer resources } \\
\hline Bearded seal & 25,680 & 1 & 68,020 & 3 \\
\hline Caribou (coastal) & 25,370 & 2 & 149,810 & 2 \\
\hline Ringed seal & 13,550 & 3 & 11,710 & 4 \\
\hline Beluga (encounter) & 14,090 & 4 & 193,370 & 1 \\
\hline Ocean fish & 8900 & 5 & 2120 & 6 \\
\hline Canada goose (canoe) & 4930 & 6 & 3590 & 5 \\
\hline Eider & 4810 & 7 & 1430 & 7 \\
\hline Codfish (rod) & 1980 & 8 & 500 & 8 \\
\hline \multicolumn{5}{|l|}{ Fall resources } \\
\hline Bearded seal & 15,000 & 1 & 68,020 & 1 \\
\hline Ringed seal & 13,010 & 2 & 20,210 & 2 \\
\hline Eider & 5160 & 3 & 1430 & 3 \\
\hline Ptarmigan & 3450 & 4 & 510 & 5 \\
\hline Brook trout & 2280 & 5 & 810 & 4 \\
\hline \multicolumn{5}{|l|}{ Winter resources } \\
\hline Caribou & 25,370 & 1 & 149,810 & 1 \\
\hline Bearded seal & 15,000 & 2 & 68,020 & 2 \\
\hline Ice netting & 14,280 & 3 & 2120 & 4 \\
\hline Ringed seal & 13,010 & 4 & 20,210 & 3 \\
\hline Ptarmigan & 2670 & 5 & 510 & 5 \\
\hline \multicolumn{5}{|l|}{ Spring resources } \\
\hline Bearded seal & 15,000 & 1 & 68,020 & 1 \\
\hline Ringed seal & 13,550 & 2 & 20,210 & 2 \\
\hline Canada goose (blind) & 3460 & 3 & 3590 & 3 \\
\hline Eider (floe edge) & 3180 & 4 & 1430 & 6 \\
\hline Ptarmigan & 2290 & 5 & 510 & 7 \\
\hline Canada goose (encounter) & 1720 & 6 & 3590 & 3 \\
\hline Lake trout & 1110 & 7 & 3060 & 5 \\
\hline
\end{tabular}

concentrated on the coast; in the winter and spring foragers divide their time between inland (terrestrial and freshwater) and coastal patches [33,34]. Terrestrial prey are dominated by caribou, but also include ptarmigan and two species of geese; marine prey include bearded seal, ringed seal, and beluga whale. In addition, one anadromous fish (Arctic char) is commonly taken in both marine and freshwater contexts. Ocean fish, such as cod, and freshwater fish, such as whitefish, lake trout and brook trout, are also taken in significant numbers.

Because the number of individuals taken in several months was low, I examined the subsistence data using the number of individuals of each species taken bimonthly. Changes in season resulted in a natural change in animal abundances. This provides a rough analogue for longer spans of archaeological time, where presumably animals would increase and decrease in abundance on the landscape in response to longer-term environmental variation and human predation as well as to seasonal variation in animal abundances. To meet the fine-grained search assumption of the prey choice model, the prey types were sorted into types from marine and terrestrial/freshwater patches $[6,28]$.
Non-subsistence items and "emergency foods" that were rarely in the Inujjuamiut diet were excluded from the database. Foxes are common prey items in Inukjuak, but their pelts are usually sold for cash and they are rarely eaten. In this situation, energy is clearly not an appropriate currency; return rates will instead be set by the price for which the fox pelts can be sold. Polar bears, which are encountered and taken extremely rarely, were excluded for the same reason. Invertebrates, which make up only a tiny fraction of the total harvest, were also excluded. Additionally, Arctic cod that were caught during jigging through sea ice were excluded from the analysis, since cod taken in this fashion are primarily used as dog food $[33,34]$. The sole Arctic hare taken during the study period was excluded as well, because this species was taken so rarely.

\subsection{Ranking of prey types}

The Inujjuamiut fauna (Table 2) are here shown ranked by return rate (kcal per h) [34] and by the total $\mathrm{kcal}$ available in the edible portion of the animal [33,34]. As mentioned earlier, in archaeological analyses body 
size is generally used as a proxy for post-encounter return rate; additionally, the handling costs of an animal can drive its return rate down. Table 2 indicates that, while there are some discrepancies between prey type resource rank and total kcal, the assumption that large body size equals higher rank is supported by these data $[5,33,34]$; a Spearman's rank-order correlation between the two measures indicates a strong and significant relationship (Spearman's rho $=0.810 ; P<0.01$ ). One of the exceptions is net fishing. In Table 2 , the entry "ocean fish" in the summer resources section refers to Arctic char caught while netting in salt-water coves. Net fishing also takes place in lakes in the autumn as freeze-up begins $[33,34]$; the return rate of this activity is entered in Table 2 as "ice netting." When these fish are taken en masse the appropriate unit of analysis becomes the harvest per net set, rather than the individual fish $[33,34]$.

Beluga whale, caribou, bearded seal, and ringed seal are the four highest-ranked resources in the Inujjuamiut set (Table 2). These four resources vary in availability by season, although some are more seasonal than others. Beluga whales are the most highly seasonal; they enter Hudson Bay in the summer, and are not available before June or after September. Caribou, while taken whenever encountered throughout the year, are encountered most often during the winter months. Likewise, many seals are caught through floe-edge and breathing-hole hunting, activities which can only take place during the winter months. Although seal return rates and harvest amounts vary seasonally (Table 2), seals are taken throughout the year.

\subsection{Variations in evenness: terrestrial and freshwater resources}

The prediction that evenness will increase as HRR decreases was tested using data from marine and terrestrial patches. Inujjuamiut subsistence is marinedominated; far fewer terrestrial resources are exploited. The most important terrestrial resource (by amount harvested) is caribou. Although caribou are hunted primarily in late fall and early winter, they are taken whenever encountered (as predicted by foraging theory), and they account for over $40 \%$ of the Inujjuamiut foraging harvest by edible calories [33,34].

Because this analysis is meant to mimic an archaeological problem, I initially identified the highest-ranked prey items in any given season as the largest terrestrial animals by body weight. According to Table 2, caribou is the only terrestrial resource that provides over 10,000 of edible kcal per item; the next largest terrestrial resource is Canada goose, at $3590 \mathrm{kcal}$ per individual. Given this difference, I considered caribou as the sole high-ranked terrestrial resource. I tested for a relation-

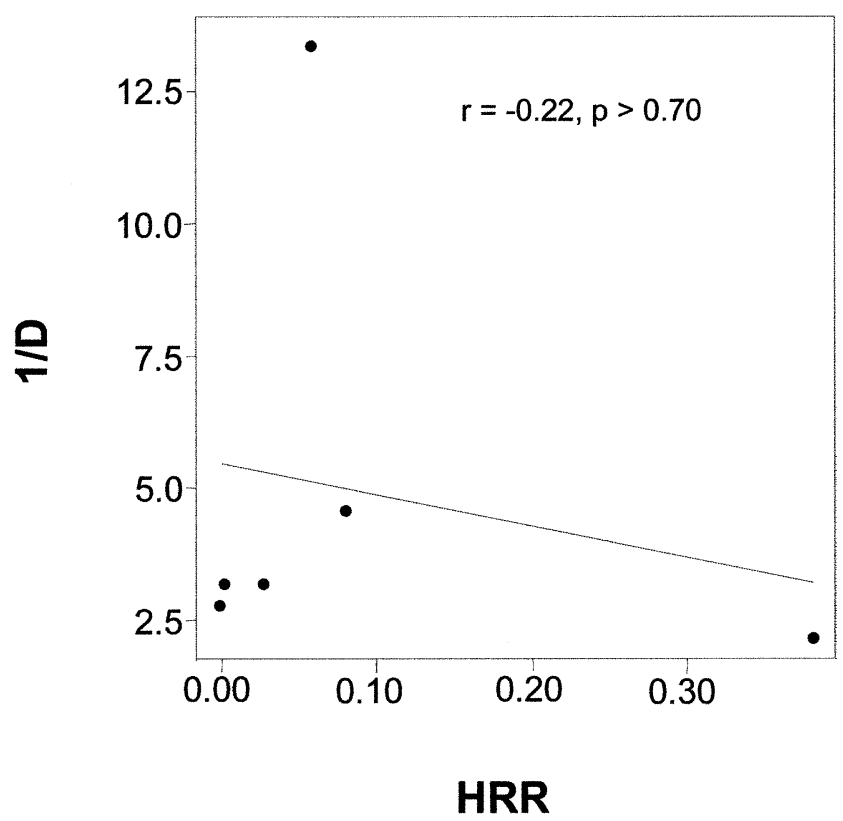

Fig. 3. Relationship of bimonthly aggregates of the inverse of Simpson's Dominance Index (1/D) to the ratio of high-ranked terrestrial resources to all terrestrial resources (HRR) based on body weight, from subsistence data collected by Smith [33,34] at Inukjuak.

ship between the bimonthly HRR and 1/D using regression (Fig. 3). No significant relationship was observed when caribou was considered the only high-ranked resource. As mentioned earlier, however, rankings of prey items do not always follow the observed kcal returns on individual species. The use of technologies that allow people to take small prey items en masse-for instance, rabbit drives in the southwestern United States - can boost the return rates of those small prey items because large numbers can be taken at one time. In these instances, the total catch is the appropriate prey item, rather then the individual prey [10,25].

As mentioned earlier, in Inukjuak fish are sometimes taken using nets. During autumn freeze-up, ice netting becomes common on the lakes; ocean net fishing is a marine hunt type among the Inujjuamiut in the summer. Dozens of fish can be taken in one net excursion, and all the fish taken in this excursion are handled at once- that is, as one prey item. This means that the return rate of one net-set of fish is higher than would be predicted than the aggregated $\mathrm{kcal}$ of the individual fish (see Table 2). In this situation "net-catch" is the appropriate prey type, rather than the individual fish [9,25]. Smith's research likewise suggests that net-catch should be considered a higher-ranked prey type [33,34].

When net-caught fish from lake-ice netting are considered a high-ranked prey type, terrestrial evenness does respond to the prevalence of two high-ranked prey types: net-caught fish and caribou. A linear regression displays a strong and significant relationship $(r=-0.83$, $P<0.05$ ) between bimonthly HRR and 1/D (Fig. 4): 


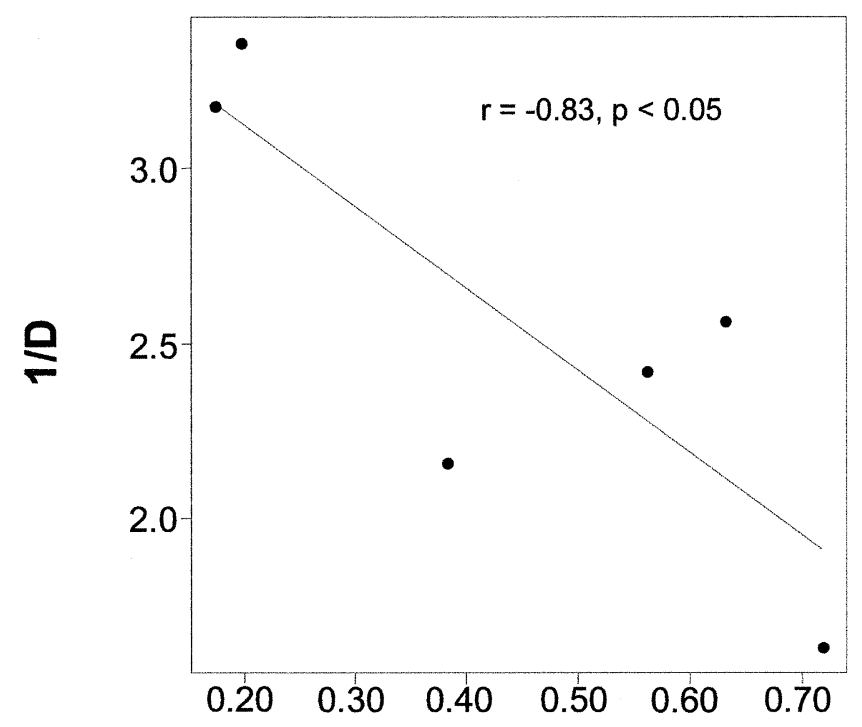

HRR

Fig. 4. Relationship of bimonthly aggregates of the inverse of Simpson's Dominance Index (1/D) to the ratio of high-ranked terrestrial resources to all terrestrial resources (HRR) based on return rates, from subsistence data collected by Smith [33,34] at Inukjuak.

evenness is low and HRR high in the late fall and winter. Caribou are most abundant in the winter, and lake-ice netting is primarily a late-fall activity. In the summer (when ice-netting is not possible and caribou are encountered less frequently), HRR is low and evenness is high. Thus, we can conclude that seasonal variations in resource abundance are driving changes in evenness.

\subsection{Variation in evenness: marine resources}

Among the marine fauna available to the Inujjuamiut, the beluga whale is the primary seasonal highranked resource. These whales are only available between June and September. The other high-ranked mammals in the marine set are bearded seal and ringed seal; these items are less seasonal in nature, although most ringed seals are taken during the winter. Additionally, fish are taken in ocean nets in the summer.

When body-weight rankings (Table 2) are used to define high-ranked resources (beluga whale, bearded seal, and ringed seal), there is no significant bimonthly correlation between HRR and 1/D (Fig. 5). However, when net-caught ocean fish are considered a high-ranked prey type, evenness responds to the prevalence of the two most seasonal high-ranked prey types: beluga whale and net-caught fish. A regression and correlation analysis displays a strong and significant relationship $(r=-0.71, P<0.01)$ between HRR and 1/D (Fig. 6). In the winter months, evenness is high and HRR is low (when the two seasonal high-ranked resources, beluga and net-catch, are absent); in the summer (when beluga

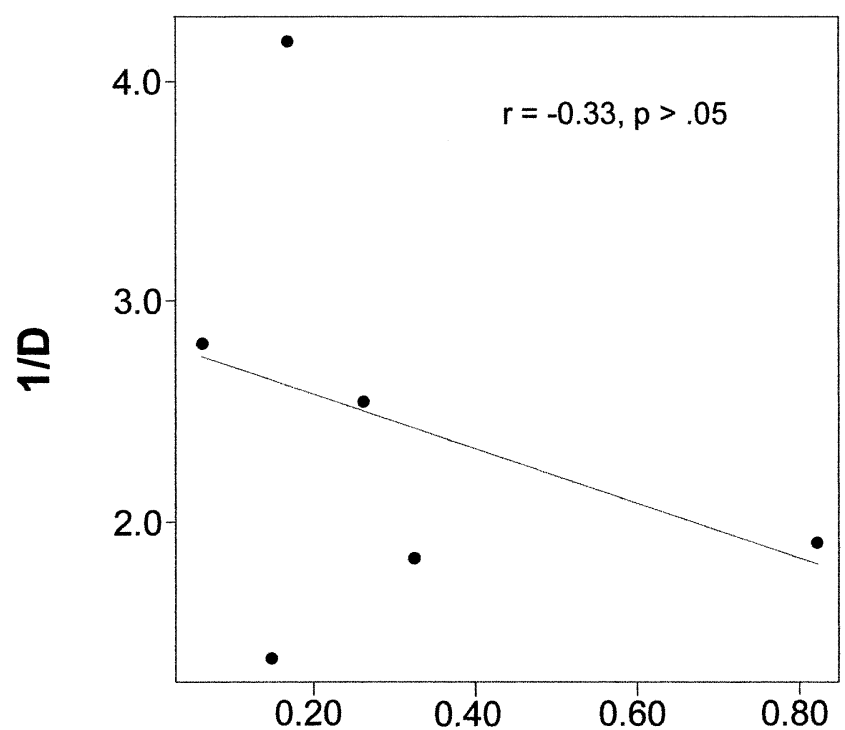

HRR

Fig. 5. Relationship of bimonthly aggregates of the inverse of Simpson's Dominance Index (1/D) to the ratio of high-ranked marine resources to all marine resources (HRR) based on body weight, from subsistence data collected by Smith $[33,34]$ at Inukjuak.

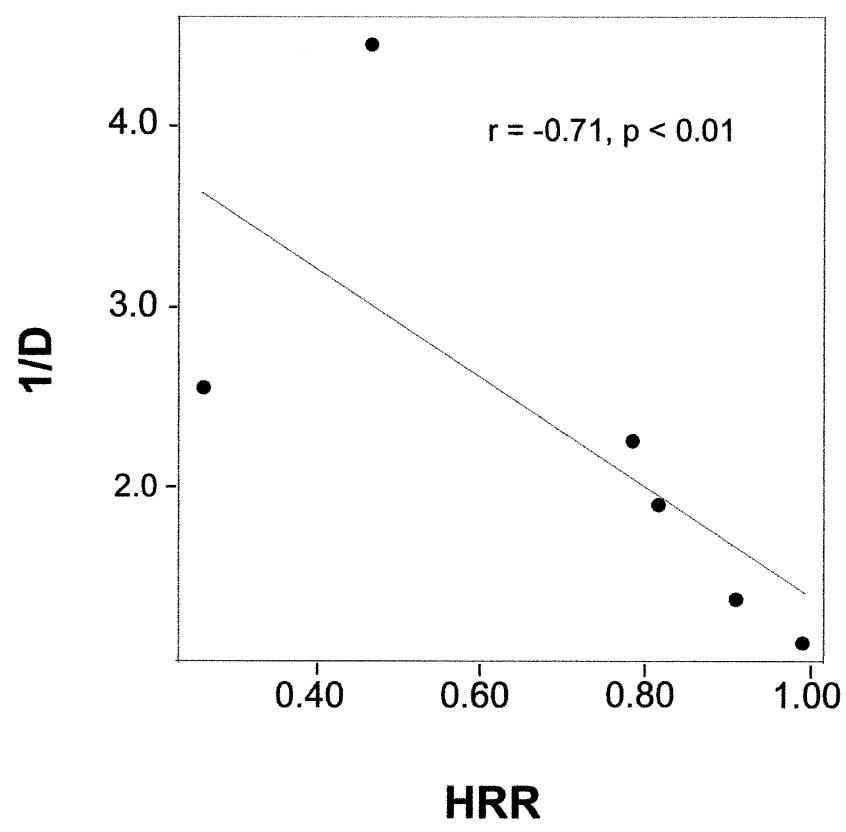

Fig. 6. Relationship of bimonthly aggregates of the inverse of Simpson's Dominance Index (1/D) to the ratio of high-ranked marine resources to all marine resources (HRR) based on return rates, from subsistence data collected by Smith $[33,34]$ at Inukjuak.

and ocean-run char are present), HRR is high and evenness is low. Thus, we can conclude that seasonal variations in resource abundance are driving changes in evenness. 


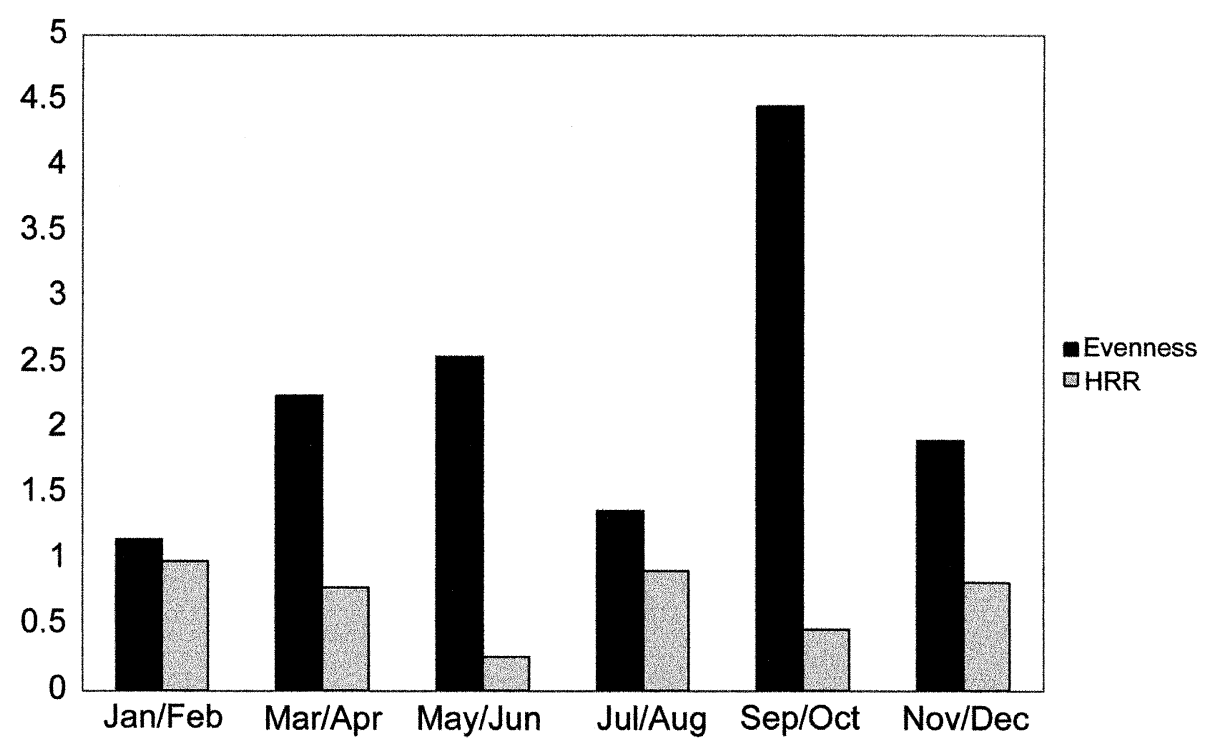

Bimonthly period

Fig. 7. Marine evenness (1/D) and relative abundance of high-ranked terrestrial prey (HRR) throughout the study period.

\section{Evenness in archaeology}

These analyses support the prediction that when one considers a set of resources that are always in the diet (controlling for variation among return rates), evenness will decrease as the percent of the highest-ranked resources increases. As encounter rates with high-ranked prey items increase, and diet breadth decreases, evenness decreases. Thus, measures of evenness can indeed provide some of the same information more commonly provided by relative abundance indices, while retaining advantages of being linked to a broader explanatory theory and being comparable across different landscapes [21].

However, the test with the Inujjuamiut data involved the use of evenness with ethnographic, rather than archaeological data. The fact that moving between ethnographic or ecological time scales and archaeological ones requires translation has been well discussed (e.g., [19]). How would the Inujjuamiut data relate to evenness if this case were archaeological? Would the test still work? Here, I discuss some factors that cause differences in the way evenness analyses can be applied to ethnographic and archaeological data, and also review some potential problems in applying evenness to archaeology.

\subsection{Time averaging}

As discussed above, the time averaging of archaeological data [19] can cause problems in evenness analyses. The data presented here involve the evenness of the diet in a bimonthly period. Fig. 7 shows how marine $1 / \mathrm{D}$ and HRR varied throughout the period of study, with low HRR and high 1/D in spring and fall, and high HRR and low 1/D in summer and winter.

However, if these data were archaeological, the evenness (1/D) and the relative abundance of high-ranked prey (HRR) would, barring the availability of seasonal harvest information, be considered for the year as a whole. In the marine case, annual $1 / \mathrm{D}$ equals 3.88 and annual HRR equals 0.70. Comparing these numbers to Fig. 7, it is clear that these averages over the ethnographic year mask considerable variation in both evenness and the percent of higher-ranked prey items in the diet.

In this case, it is easy to see what the time-averaged values (3.88 and 0.70) mean-they are the average evenness and HRR for a group of marine foragers throughout a year. In an archaeological case, however, these values could reflect anything from one foraging event to accumulated harvests over hundreds of years. Evenness in the archaeological case would represent the average evenness of diets at that site, rather than the evenness of the diet of one group of people. And whether HRR and 1/D would maintain their relationship in such an averaged case has yet to be determined.

\subsection{Nestedness and close-return prey items}

Another potential problem mentioned earlier concerns the possibility that increasing evenness in any given case reflects increasing abundance of a number of high-ranked prey items, rather than decreasing availability of one dominant high-ranked item. Testing for this in an archaeological case requires an analysis of nestedness, an approach first suggested by Grayson and 
Table 3

Nestedness of the terrestrial fauna throughout the study period. Nestedness temperature [29] is $1.02^{\circ}(P=0.01)$

\begin{tabular}{lllll}
\hline & Summer & Fall & Winter & Spring \\
\hline Brook trout & $\times$ & $\times$ & & $\times$ \\
Canada goose & & & & $\times$ \\
Caribou & $\times$ & $\times$ & $\times$ & $\times$ \\
Char & $\times$ & $\times$ & $\times$ & $\times$ \\
Cod & $\times$ & & & $\times$ \\
Eider & $\times$ & $\times$ & & $\times$ \\
Lake trout & $\times$ & $\times$ & $\times$ \\
Otter & $\times$ & $\times$ & $\times$ & $\times$ \\
Ptarmigan & $\times$ & & & $\times$ \\
Sculpin & & & & $\times$ \\
Snow goose & $\times$ & $\times$ & $\times$ & $\times$ \\
Whitefish & & & & \\
\hline
\end{tabular}

Delpech [19]. To assess nestedness for the Inujjuamiut case, I used Patterson and Atmar's [29] Nestedness Calculator, which presents a measure of the degree of nestedness in a presence-absence matrix. The Calculator measures "system temperature": 0 degrees indicates a perfectly nested ("cool") subset, and 100 degrees a completely random order, or a "hot" system. In addition, the Nestedness Calculator can provide a measure of the probability that the assemblages for analysis would be drawn randomly.

Table 3 shows a nestedness matrix of the terrestrial Inujjuamiut data set broken into seasons. In an archaeological case, if encounter rates with higher-ranked prey were declining through time, we would expect earlier assemblages to be nested subsets of later ones. In this case, we can see that winter and fall diets are nested subsets of summer and especially spring ones. This makes sense as the two highest-ranked terrestrial resources (caribou and ice netting) are scarce or unavailable during spring and summer. The Nestedness Calculator gives a system temperature of 1.02 degrees, indicating an extremely nested group of assemblages. The Monte Carlo-derived probability that this nestedness matrix was randomly generated is less than 0.01 .

Table 4 shows the nestedness matrix for the Inujjuamiut marine data. In this case, the "system temperature" provided by the Nestedness Calculator is 10.37 degrees, with a Monte Carlo-derived probability that the matrix was randomly generated of 0.02 . While this is still a fairly nested set of assemblages, the system temperature is higher than might be expected. The presence-absence matrix shown in Table 4 also reveals some surprising information. The highest-ranked resources in the marine set (bearded seal, beluga whale, ocean-net fishing, and ringed seal) are most abundant during summer and winter, so in this case we would expect winter and summer to be nested subsets of spring and fall assemblages. While the winter assemblage is a subset of other seasons, the summer one is the widest in
Table 4

Nestedness of the marine fauna throughout the study period.

Nestedness temperature [29] is $10.37^{\circ}(P=0.02)$

\begin{tabular}{lcccc}
\hline & Summer & Fall & Winter & Spring \\
\hline Bearded seal & $\times$ & $\times$ & $\times$ & $\times$ \\
Beluga & $\times$ & $\times$ & & \\
Brook trout & $\times$ & $\times$ & & \\
Canada goose & $\times$ & & & \\
Char & $\times$ & $\times$ & & \\
Cod & $\times$ & & & \\
Eider & $\times$ & & $\times$ & $\times$ \\
Guillemot & $\times$ & & & \\
Lake trout & $\times$ & $\times$ & & \\
Loon & $\times$ & & & \\
Merganser & $\times$ & $\times$ & & \\
Ptarmigan & & $\times$ & $\times$ & \\
Ringed seal & $\times$ & $\times$ & $\times$ & \\
Sculpin & $\times$ & & & \\
Snow goose & $\times$ & & & \\
\hline
\end{tabular}

the entire data set. This may be because in spring and fall, foraging is concentrated in terrestrial patches, and so few marine resources are taken at all $[33,34]$.

This suggests that the patch choice model-which predicts how long a forager should stay in a particular patch [24,35] - may complicate nestedness analyses. When returns from the marine patch drop below a certain threshold, as they do in the spring and fall [33,34], the marine patch is abandoned, though prey may be occasionally taken in the course of other activities. Hence few species are included in the marine spring and fall columns, even though our predictions suggest that winter and summer assemblages should be nested subsets of spring and fall ones.

\subsection{Mass capture technologies}

One potential problem in translating evenness analyses to archaeological settings that was highlighted by this analysis concerns the complications of mass capture analyses. Many authors $[10,18,25]$ have pointed out ways in which the mass capture problem can complicate analyses that rely upon relative abundance indices. The Inujjuamiut case highlights at least two ways in which they can complicate evenness analyses.

In the analysis presented here, I treated these data as if they were archaeological, and thus looked at the total number of individual fish caught in a net rather than counting each net full of fish as one prey item. In this case, running the data using the number of nets full of fish rather than the total number of individual fish caught in nets makes little difference; although HRR values are significantly lower when net-pulls are used, evenness values remain about the same for each bimonthly period, and the relationship through time between HRR and 1/D is negative and significant using 
both methods. Whether this would be the same in another case is impossible to tell without additional tests; as archaeologists could not use net-pulls as their harvest unit, this could be a significant problem.

In this particular data set, the key problem did not concern units of analysis but was one of mass collecting. For the Inujjuamiut, net fishing provides a far higher return rate for fish than would be expected from their individual body sizes. This means that archaeologists interested in optimal foraging models and prey choice must devise methods of separating animals taken en masse from those hunted singly (also discussed in $[17,24])$. If the data presented here were archaeological, it would be difficult (if not impossible) to distinguish fish caught in nets from those taken singly (see [8]), especially as most species in this assemblage are routinely taken both in nets and by rod.

It is important to note that this difficulty - the lack of equality between return rates and body size-extends beyond prey items taken en masse. Beluga, for instance, has a return rate far lower than one would expect from its size, because after a certain point large size will increase handling costs disproportionately relative to caloric value. Similarly, the return rate of bearded seal is far lower than one would expect given its return based simply on available kcal (Table 2). The larger problem here is that when the correlation between body size and return rates does not hold, then prey choice-based analyses - including evenness analyses - that use body size as a proxy for return rate will not work.

Another potential problem in using evenness concerns variation among prey return rates. In order to understand evenness within the context of prey choice at all, one must have a clear understanding of the ranking of prey types. If two resources are high-ranked enough that they are always in the diet, and are encountered with equal frequency, the numbers of each taken should be statistically equivalent (assuming equal pursuit success rates). If these two high-ranked resources were sufficiently abundant one would expect high evenness because only those two resources would be taken, and they would be pursued whenever encountered. Thus, archaeologists treating these taxa as different prey types will find increased evenness values in periods when these prey types become more abundant.

Both of these confounding factors suggest that the assumptions that archaeologists make about prey types and resource return rates may in many cases be unwarranted. To improve the validity of archaeological applications of foraging theory, we need to develop methods to ascertain when our assumptions are violated.

\section{Discussion and conclusions}

The Inujjuamiut data presented here support the hypothesis that increasing dietary evenness can reflect increasing dietary breadth and/or decreasing availability of preferred prey types. As encounter rates with highranked prey items decrease, and diet breadth increases, evenness increases, and vice versa. However, the complexity of archaeological data may make evenness difficult to apply in at least some archaeological settings. In particular, close-return prey items, and mass harvest issues can complicate archaeological dietary evenness analyses. Additional studies are needed to clarify how serious these problems are; in the absence of such information, however, methods for identifying situations in which evenness may not work are available. Nestedness analyses can be used to identify situations in which close-return prey items may cause problems (though attention should be paid to patch choice issues when using them). Mass harvest situations are more complicated, as identifying them depends on the availability of prey type-specific protocols. Fortunately, such protocols are increasingly available $[8,11,31]$.

The expectation that evenness would avoid all the problems posed by relative abundance indices is, of course, unrealistic. Although evenness measures do share some problems with relative abundance indices, the advantages of evenness - comparability, developed explanatory theory - may make it an extremely useful tool for zooarchaeologists. Despite problems, evenness measures did provide valid insights in this test. Additional tests of the evenness-prey choice relationship are necessary. However, this test confirms that dietary evenness, in at least some situations, can be used by archaeologists to understand changing prehistoric encounter rates with prey $[17,19-21,36]$.

\section{Acknowledgements}

Special thanks are due to Eric Smith and Donald Grayson, who guided me through this project from start to finish. I also thank Jack Broughton, Mike Cannon, Ben Fitzhugh, Carol Frey, Tom Minichillo, James O'Connell, Andrew Ugan, and two anonymous reviewers, all of whom provided useful feedback on earlier versions of this manuscript.

\section{References}

[1] R.D. Bardgett, A.C. Jones, D.L. Jones, S.J. Kemmitt, R. Cook, P.J. Hobbs, Soil microbial community patterns related to the history and intensity of grazing in sub-montane ecosystems, Soil Biology \& Biochemistry 33 (2001) 1653-1664.

[2] R.E. Bodmer, J.F. Eisenberg, K.H. Redford, Hunting and the likelihood of extinction of Amazonian mammals, Conservation Biology 11 (1997) 460-466.

[3] J.M. Broughton, Declines in mammalian foraging efficiency during the Late Holocene, San Francisco Bay, California, Journal of Anthropological Archaeology 13 (1994) 371-401. 
[4] J.M. Broughton, Late Holocene resource intensification in the Sacramento Valley, California: the vertebrate evidence, Journal of Archaeological Science 21 (1994) 501-514.

[5] J.M. Broughton, Resource Depression and Intensification during the Late Holocene, San Francisco Bay: Evidence from the Emeryville Shellmound Vertebrate Fauna, Ph.D. thesis, University of Washington, 1995.

[6] J.M. Broughton, Resource Depression and Intensification During the Late Holocene, San Francisco Bay: Evidence from the Emeryville Shellmound, University of California Press, Berkeley, California, 1999.

[7] J.M. Broughton, D.K. Grayson, Diet breadth, Numic expansion, and the White Mountains faunas, Journal of Archaeological Science 20 (1993) 331-336.

[8] V.L. Butler, Tui chub taphonomy and the importance of marsh resources in the Western Great Basin of North America, American Antiquity 61 (1996) 699-717.

[9] M.D. Cannon, Large mammal relative abundance in Pithouse and Pueblo period archaeofaunas from southwestern New Mexico: resource depression among the Mimbres-Mogollon? Journal of Anthropological Archaeology 19 (2000) 317-347.

[10] M.D. Cannon, Rabbit Drives, Resource Depression, and the Artiodactyl Index, Paper presented at the Society for American Archaeology meetings, April 2000, Philadelphia, PA, 2000.

[11] M.D. Cannon, Large Mammal Resource Depression and Agricultural Intensification: An Empirical Test in the Mimbres Valley, New Mexico, Ph.D. thesis, University of Washington, 2001.

[12] C.G. Curtin, Can Montane landscapes recover from human disturbance-long-term evidence from disturbed sub-alpine communities, Biological Conservation 74 (1995) 49-55.

[13] D.H.K. Fairbanks, M. Kshatriya, A.S. van Jaarsveld, L.G. Underhill, Scales and consequences of human land transformation on South African avian diversity and structure, Animal Conservation 5 (2002) 61-74.

[14] C.D. FitzGibbon, H. Mogaka, J.H. Fanshawe, Subsistence hunting in Arabuko-Sokoke Forest, Kenya, and its effects on mammal populations, Conservation Biology 9 (1995) 1116-1126.

[15] D.K. Grayson, The effects of sample size on some derived measures in vertebrate faunal analysis, Journal of Archaeological Science 8 (1981) 77-88.

[16] D.K. Grayson, Archaeological associations with extinct Pleistocene mammals in North America, Journal of Archaeological Science 11 (1984) 213-221.

[17] D.K. Grayson, Mammalian responses to Middle Holocene climatic change in the Great Basin of the Western United States, Journal of Biogeography 27 (2000) 181-192.

[18] D.K. Grayson, M.P. Cannon, Human paleoecology and foraging theory in the Great Basin, in: C. Beck, C. Beck, D. Rhode, R. Elston (Eds.), Models for the Millennium: Great Basin Anthropology Today, University of Utah Press, Salt Lake City, 1999.

[19] D.K. Grayson, F. Delpech, Changing diet breadth in the Early Upper Paleolithic of Southwestern France, Journal of Archaeological Science 25 (1998) 1119-1130.

[20] D.K. Grayson, F. Delpech, The Upper Paleolithic at Grotte XVI (Dordogne, France): richness, evenness, and cave bears, in: M.A. Hays, P. Thacker (Eds.), Questioning the Answers: Resolving Fundamental Problems of the Early Upper Paleolithic, British Archaeological Reports, Oxford, 2002.

[21] D.K. Grayson, F. Delpech, J.-P. Rigaud, J.F. Simek, Explaining the development of dietary dominance by a single ungulate taxon at Grotte XVI, Dordogne, France, Journal of Archaeological Science 28 (2001) 115-125.

[22] J.S. He, F.A. Bazzaz, B. Schmid, Interactive effects of diversity, nutrients and elevated $\mathrm{CO}_{2}$ on experimental plant communities, Oikos 97 (2002) 337-348.
[23] H. Hirst, I. Juttner, S.J. Ormerod, Comparing the responses of diatoms and macroinvertebrates to metals in upland streams of Wales and Cornwall, Freshwater Biology 47 (2002) 1752-1765.

[24] R.L. Kelly, The Foraging Spectrum: Diversity in HunterGatherer Lifeways, Smithsonian Institution Press, Washington, DC, 1995.

[25] D.B. Madsen, D.N. Schmitt, Mass collecting and the diet breadth model: a great basin example, Journal of Archaeological Science 25 (1998) 445-455.

[26] A.E. Magurran, Ecological Diversity and its Measurement, Princeton University Press, Princeton, NJ, 1988.

[27] S. Mille-Pagaza, J. Carrillo-Laguna, A. Perez-Chi, M.E. Sanchez-Salazar, Abundance and diversity of littoral invertebrates of Socorro Island, Revillagigedo Archipelago, Mexico, Revista De Biologia Tropical 50 (2002) 97-105.

[28] L. Nagaoka, Using diversity indices to measure changes in prey choice at the Shag River Mouth Site, Southern New Zealand, International Journal of Osteoarchaeology 11 (2001) 101-111.

[29] B.D. Patterson, W. Atmar, The Nestedness Calculator: A Visual Basic Program, Including 294 Presence-Absence Matrices, Chicago, 1995.

[30] E.C. Pielou, An Introduction to Mathematical Ecology, Wiley, New York, 1969.

[31] K.M. Schmidt, The Five Feature Site (AZ Cc:7:55[ASML): evidence for a prehistoric rabbit drive in Southeastern Arizona, Kiva 65 (1999) 103-124.

[32] M.C. Scott, G.S. Helfman, Native invasions, homogenization, and the mismeasure of integrity of fish assemblages, Fisheries 26 (2001) 6-15.

[33] E.A. Smith, Evolutionary Ecology and the Analysis of Human Foraging Behavior: An Inuit Example from the East Coast of Hudson Bay, Ph.D. thesis, Cornell University, 1980.

[34] E.A. Smith, Inujjuamiut Foraging Strategies: Evolutionary Ecology of an Arctic Hunting Economy, Aldine de Gruyter, Hawthorne, NY, 1991.

[35] D.W. Stephens, J.R. Krebs, Foraging Theory, Princeton University Press, Princeton, NJ, 1986.

[36] M.C. Stiner, Thirty years on the "Broad Spectrum Revolution" and Paleolithic demography, Proceedings of the National Academy of Sciences of the United States of America 98 (2001) 6993-6996.

[37] M.C. Stiner, N.D. Munro, T.A. Surovell, The tortoise and the hare: small-game use, the broad-spectrum revolution, and Paleolithic demography, Current Anthropology 41 (2000) 39-73.

[38] M.C. Stiner, N.D. Munro, T.A. Surovell, E. Tchernov, O. Bar-Yosef, Paleolithic population growth evidenced by small animal exploitation, Science 283 (1999) 190-194.

[39] B.J. Wilsey, C. Potvin, Biodiversity and ecosystem functioning: importance of species evenness in an old field, Ecology 81 (2000) 887-892.

[40] E.S. Wing, Vertebrate remains from the Wash Island Site, Florida Anthropologist 16 (1963) 93-96.

[41] E.S. Wing, Hunting and herding in the Peruvian Andes, in: A.T. Clason (Ed.), Archaeozoological Studies, North Holland Publishing, Amsterdam, 1975, pp. 302-308.

[42] B. Winterhalder, E.A. Smith, Analyzing adaptive strategies: human behavioral ecology at twenty-five, Evolutionary Anthropology 9 (2000) 51-72.

[43] R.S. Woodd-Walker, P. Ward, A. Clarke, Large-scale patterns in diversity and community structure of surface water copepods from the Atlantic Ocean, Marine Ecology_-Progress Series 236 (2002) 189-203. 